\title{
KAJIAN ELEMEN PEMBENTUK SUASANA RUANG BERTEMA KOREAN STREET VIEW PADA INTERIOR KAFE CHINGU DI BANDUNG
}

\author{
Mahendra Nur Hadiansyah, Dessy Fitrah Ramadhani \\ (Email: mahendrainterior@telkomuniversity.ac.id) \\ Program Studi Desain Interior \\ Fakultas Industri Kreatif \\ Universitas Telkom \\ Jl. Telekomunikasi No.1, Bandung, Indonesia
}

\begin{abstract}
ABSTRAK
Peran desain interior dalam sebuah industri kreatif harus memenuhi tiga tujuan yaitu, fungsi, estetika, dan kebutuhan psikologis pengunjung. Pada sebuah kafe, suatu desain dapat dikatakan sukses apabila kafe tersebut ramai pengunjung dan menjadi tren di masyarakat sekitarnya. Salah satu tren kafe saat ini yaitu bertema Korea. Maraknya budaya Korea yang masuk ke dunia internasional yang didukung oleh akses internet dan sosial media pada era globalisasi menghadapkan masyarakat indonesia dengan hallyu wave atau demam Korea melalui aneka hiburan dan informasi. Kafe Chingu yang berada di kota Bandung menggunakan tema Korean street view untuk menarik pengunjung pecinta budaya Korea. Penelitian ini bertujuan untuk mengetahui proses bagaimana elemen interior terbentuk sehingga mampu menggiring persepsi pengunjung kafe Chingu merasakan suasana bertemakan Korean street view. Metode yang diterapkan yaitu metode kualitatif berupa pengumpulan data melalui survey dan dokumentasi serta forum grup diskusi. Berdasarkan hasil penelitian terdapat beberapa elemen yang mempengaruhi pengunjung dalam merasakan suasana Korean street view yaitu arsitektural rumah tradisional korea, elemen interior seperti mural, signage, neon box dan elemen dekoratif seperti dinding dengan papan bertulis huruf Hangeul, bunga sakura, dan mesin minuman yang menggambarkan suasana di perkotaan Korea Selatan. Pengunjung dapat merasakan suasana tematik tersebut berdasarkan pengalaman dari menonton acara-acara Korea atau video vlog traveling di Korea pada internet. Pada dasarnya pembentukan suasana ruang melalui elemen interior pada Kafe Chingu memanfaatkan stereotipe yang hadir di masyarakat tentang Korea.
\end{abstract}

Kata Kunci: kafe; tren; Korea; hallyu; elemen interior

ABSTRACT
The role of interior design in creative industry has to accommodate to three goals; function,
aesthetic, and visitor's pyschological state. In a cafe, a designer can be counted as a success if the
cafe has a high visitor number and becomes a trend in the local society. One of the café is a popular
trend of Korean Theme made famous internationally through the internet and social media in this
era of globalization which the Indonesian people exposed to hallyu wave or the Korean fever.
Chingu Café located in Bandung that adapts Korean Street View theme to attract visitors who
idolize Korean culture. This research aims to determine how the process of interior elements are
formed so as to lead the visitor perceptions of Chingu cafe feel the atmosphere themed Korean
street view. The method used in this research is qualitative method which include data collecting
(via survey), documentation, and group discussion. Based on this research, there are a few
elements that attracts visitors; traditional Korean house architecture, interior elements such as
mural, signage, neon box, and decorative elements that resembles the elements on Korean streets 
such as wall with Korean writings, Sakura flower, and vending machines that depict the atmosphere in urban of South Korea. Visitors can feel the thematic atmosphere based on experiences from watching Korean shows or vlog videos traveling in Korea on the internet. Basically, the establishment of an atmosphere of space through the interior elements utilize Chingu café used stereotypes in society about Korea.

Keywords: cafe; trend; Korea; hallyu; interior element

\section{PENDAHULUAN}

Maraknya budaya Korea yang masuk ke dunia internasional didukung oleh akses internet dan sosial media pada era globalisasi ini. Budaya Korea masuk ke berbagai negara melalui hallyu wave atau Korean fever yang biasa disebut dengan demam Korea. Kepopuleran budaya Korea Selatan dikemas dalam produk industri hiburan berupa tontonan acara televisi seperti serial drama, reality show, musik dan film layar lebar dengan sangat kreatif. Budaya populer Korea Selatan akhirnya menyebar ke seluruh dunia dengan mudah melalui media internet yang semakin maju (Hadiansyah dan Hendrawan, 2020). Budaya tersebut akhirnya mendapat respon positif dari negara-negara lain. Reaksi positif yang diberikan oleh masyarakat banyak menjadikan hallyu wave hadir sebagai kejadian transnasional yang mengubah banyak sudut pandang berbagai negara di dunia terhadap budaya asing yang masuk ke dalam negaranya (Sari dan Jamaan, 2014).

Salah satu negara yang terpengaruh dengan adanya hallyu wave adalah Indonesia. Masyarakat Indonesia terutama kaum milenial banyak mengetahui tentang hallyu wave melalui drama, reality show, K-pop, vlogger sampai makeup dan fashion khas Korea yang dipakai oleh banyak influencer dunia. Penyebaran hallyu wave di Indonesia memberikan dampak positif bagi hubungan kerjasama antara Korea dan Indonesia.

Masyarakat mulai tertarik dengan dunia Korea karena mudahnya mencari informasi melalui internet. Salah satu media yang sering memperbaharui atau mengangkat tentang kehidupan perkotaan atau negeri Korea adalah youtube. Pada media ini, mulai banyak pencipta konten yang mengangkat topik tentang kehidupan dan suasana perkotaan Korea Selatan, mulai dari vlogger mancanegara sampai domestik. Akibat dari maraknya buadaya Korea yang ada, penjualan aksesoris, makeup, fashion sampai hiburan Korea seperti drama dan konser music turut meningkat (Hadiansyah, et.al, 2019). Salah satu vlogger asal Indonesia dengan pakaian K-pop style dan juga penikmat musik Korea adalah Ria SW. Pada kanal 
Serat Rupa Journal of Design, July 2021, Vol.5, No.2: 166-185

E-ISSN: 2477-586X, ISSN: 2338-3348 | https://doi.org/srjdv5i2.2836 | Received: 13-08-2020 Accepted: 03-04-2021 Mahendra Nur Hadiansyah, Dessy Fitrah Ramadhani

Kajian Elemen Pembentuk Suasana Ruang Bertema Korean Street View pada Interior Kafe Chingu di Bandung

youtube-nya (https://youtu.be/Vutfjx8iP5k), Ria juga membagikan pengalamannya tentang street food di Korea. Selain itu, kanal youtube Ria mengeksplorasi tentang keindahan jalanan kota besar di Korea. Bagaimana kehidupan perkotaan Korea sampai suasana malam hari yang indah di negeri gingseng tersebut. Keindahan jalanan kota besar di sana identik dengan mural, signage atau petunjuk arah, bentuk halte bus yang khas, sampai gemerlap lampu kota dan neon box yang sering kali muncul pada tayangan drama, musik video, sampai reality show Korea.

Kondisi maraknya Hallyu Wave yang masuk ke Indonesia dimanfaatkan baik oleh para pengusaha kafe. Ada banyak faktor yang dapat mempengaruhi peningkatan pengunjung pada kafe diantaranya dengan meningkatkan kualitas menu, sistem pelayanan sampai membuat konsep interior yang unik. Desain interior yang bertematik dan berkarakter berperan penting sebagai ciri khas bagi ruang dan sekaligus memberikan kondisi yang tepat untuk menciptakan citra yang diinginkan (Kusumowidagdo, 2005). Salah satunya adalah kafe Chingu yang berada di Buah Batu, Bandung. Kafe Chingu mengusung tema Korean street view melalui penerapan elemen desain interior. Kafe Chingu membangun persepsi pengunjung dengan menjuluki dirinya The Little of Seoul, yang berarti sebuah miniatur ibu kota Korea selatan, yaitu kota Seoul. Interior kafe Chingu dalam mewujudkan tematik ruang tentu tak lepas dari peran elemen pembentuk interiornya. Elemen interior dalam kafe Chingu inilah yang akan mempengaruhi persepsi pengunjung hingga terbawa pada pengalaman akan informasi dan wawasan terhadap budaya Korea. Proses pencarian dan penggunaan referensi desainer terhadap stereotipe yang melekat di kalangan masyarakat tentang Korea merupakan cikal bakal terbentuknya elemen interior didalam proses desain. Disinilah pentingnya mengetahui proses bagaimana sebuah elemen interior terbentuk berdasarkan referensi sehingga mampu membawa persepsi pengunjung merasakan sebuah suasana bertema Korean Street View.

\section{METODE PENELITIAN}

Metode yang digunakan adalah metode kualitatif yang dipadukan dengan forum grup dsikusi. Menurut Anggito dan Setiawan (2018), metode kualitatif adalah penelitian dengan cara mengumpulkan data suatu objek atau situasi secara rinci karena suatu fenomena objek tertentu terhadap subjek. Penggalian data langsung didapatkan oleh penulis melalui sebuah pengamatan dan dokumentasi. Tahapan yang dilakukan melalui beberapa tahapan yaitu pengumpulan data melalui survey dan juga dokumentasi, forum grup diskusi 
Serat Rupa Journal of Design, July 2021, Vol.5, No.2: 166-185

E-ISSN: 2477-586X, ISSN: 2338-3348 | https://doi.org/srjdv5i2.2836 | Received: 13-08-2020 Accepted: 03-04-2021 Mahendra Nur Hadiansyah, Dessy Fitrah Ramadhani

Kajian Elemen Pembentuk Suasana Ruang Bertema Korean Street View pada Interior Kafe Chingu di Bandung

beranggotakan pengunjung yang diambil sampel secara acak dari kalangan pengunjung yang sedang berada pada kafe Chingu. Pengambilan sampel pengunjung dibagi menjadi beberapa kalangan yaitu remaja berusia 11 hingga 19 tahun, dewasa 20 hingga 60 tahun, dan lansia diatas 60 tahun. Forum grup diskusi dilaksanakan dengan tujuan untuk mendapatkan persepsi atas suasana yang dirasakan langsung oleh subjek yaitu pengunjung kafe terkait obejek dalam ruang yang mampu membangun suasana jalanan di perkotaan Korea. Agar lebih spesifik mendapatkan sumber pembangun persepsi dari responden forum grup diskusi, selanjutnya responden dipilih secara spesifik sebagai penggemar dan penikmat hallyu wave untuk melanjutkan diskusi kembali secara mendalam dengan menunjukan sumber pengalaman yang membangun persepsi mereka. Sebagian besar penggemar dan penikmat hallyu wave berada pada antara usia 15 hingga 40 tahun. Tahap berikutnya dilakukan studi literatur sebagai pedoman analisis data yang dikomparasikan melalui studi banding tentang kondisi interior kafe dengan cuplikan keadaan kondisi asli di Korea yang disajikan melalui konten-konten yang berada di internet seperti vlog, drama korea, dan video klip maupun artikel atau blog yang mengulas dan menampilkan foto keadaan yang ada di perkotaan Korea berdasarkan hasil forum grup diskusi yang sudah dilakukan. Selanjutnya data yang diperoleh dianalisis lebih dalam dengan mengamati objek baik secara langsung di lapangan maupun melalui data dokumentasi. Upaya pengamatan terhadap elemen pembentuk tematik ruang berdasarkan ciri, sifat, dan karakternya dilakukan untuk mengetahui bagaimana keserupaan objek dengan stereotipe budaya Korea yang melekat di masyarakat sehingga dapat menggiring persepsi pengunjung Kafe Chingu.

\section{PEMBAHASAN}

Kafe Chingu terdapat di beberapa kota, yaitu Jakarta, Bandung, dan Yogyakarta. Di kota Bandung sendiri terdapat dua lokasi yaitu di daerah Tamansari dan Buah Batu. Penelitian ini terfokus pada salah satu kafe Chingu yang ada di Bandung tepatnya yang berada di Jl. Buah Batu No.218, Cijagra, Lengkong, Kota Bandung, Jawa Barat 40265. Lokasi ini dipilih karena karakternya yang unik dengan minimnya keterbatasan lahan yang ada, namun masih mampu memaksimalkan tematik dalam ruang. Chingu memanfaatkan dengan maksimal lahan yang dimilikinya secara vertikal. Luasan lahan yang terbatas membuat sang pemilik memaksimalkan jumlah kapasitas pengunjung dengan cara membuat bangunan bertingkat sebanyak tiga lantai. Kafe Chingu sangat kental dengan sajian menu Korea, untuk menambah kesan Korea di mata pengunjung interior disajikan dengan beragam pernak 
pernik yang lucu khas negeri ginseng yang sangat disukai oleh para pecinta budaya Korea khususnya para remaja.

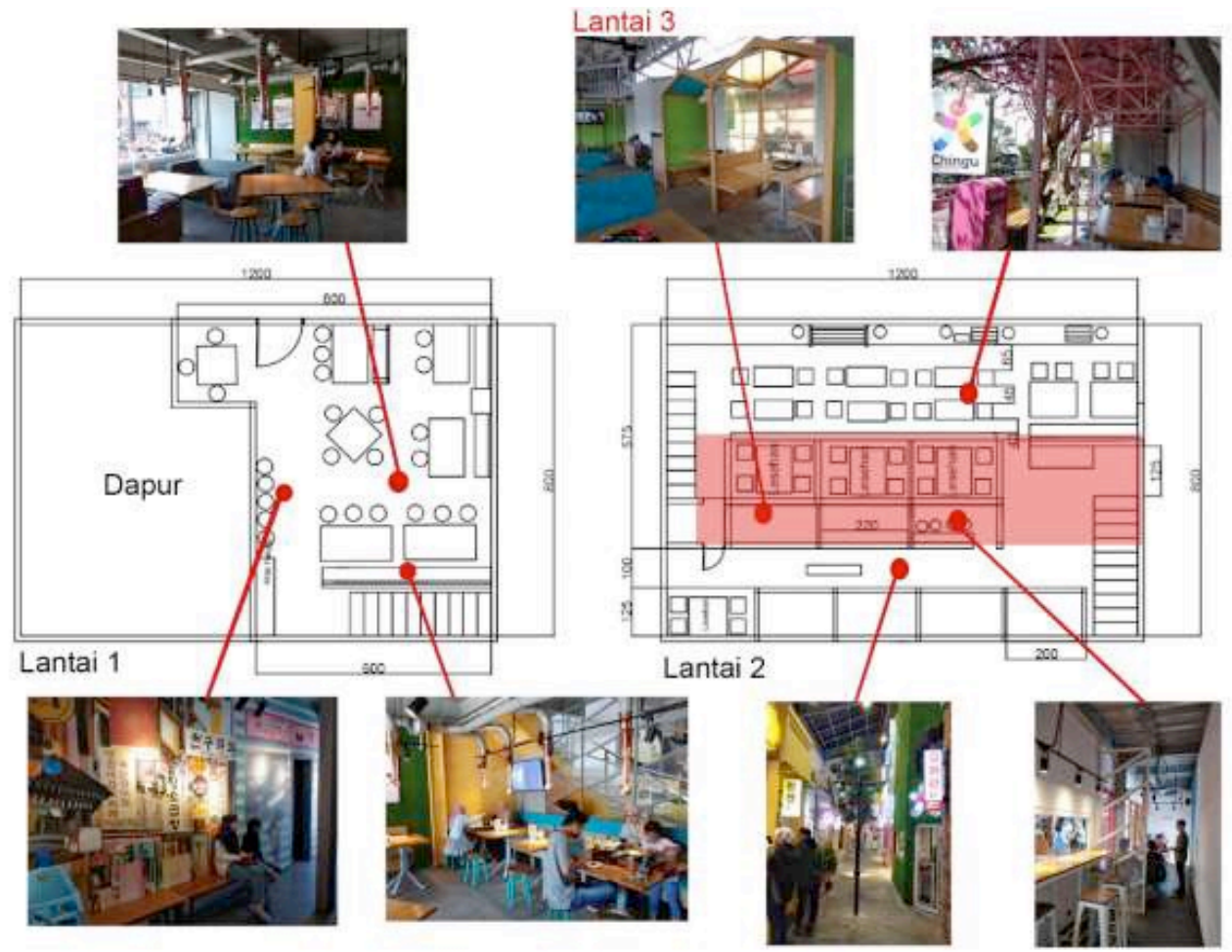

Gambar 1. Denah dan suasana Kafe Chingu Sumber: Olah Data Penulis, 2020

Pada lantai satu, pertama kali masuk pengunjung langsung diberikan kesan berjalan pada sebuah jalanan di perkotaan Korea. Sirkulasi utama secara perseptual pengunjung terasa berjalan di samping sebuah tempat makan yang khas ditampilkan dipinggiran jalanan kota di Korea dengan konsep yang terbuka dan penuh dengan pemandangan gemerlap lampu, neon box, dan papan nama di atas bangunan melalui sebuah perspektif mural pada dinding.

Pada lantai dua, suasana jalanan perkotaan Korea semakin kental terasa. Hal tersebut disebabkan karena ruas sirkulasi utama lebih lebar dibandingkan dengan dengan lantai satu. Kondisi volume ruang yang tinggi membuat kesan luas dan berada di luar ruang meski kenyataanya berada di dalam sebuah ruangan tertutup. Di kanan dan kiri sirkulasi area ini dibuat menyerupai bangunan-bangunan pertokoan, kafe-kafe, bahkan bioskop yang ada dijalanan-jalanan terkenal diperkotaan Korea. Suasana yang lain dari pada yang lain inilah kerap dimanfaatkan para pengunjung untuk ber-swa foto. 
Serat Rupa Journal of Design, July 2021, Vol.5, No.2: 166-185

E-ISSN: 2477-586X, ISSN: 2338-3348 | https://doi.org/srjdv5i2.2836 | Received: 13-08-2020 Accepted: 03-04-2021 Mahendra Nur Hadiansyah, Dessy Fitrah Ramadhani

Kajian Elemen Pembentuk Suasana Ruang Bertema Korean Street View pada Interior Kafe Chingu di Bandung

Masih di lantai yang sama, menuju arah bagian depan dari bangunan, area terkonsep sebagian besar sisi ruang terbuka menghadap bagian depan dari bangunan. Kondisi perkotaan masih tetap terasa dengan ciri khas kota besar di Korea Selatan dengan meletakan beberapa pohon sakura buatan. Warna dedaunan yang dominan berwarna pink menghiasi hampir seluruh bagian atas tempat duduk pada area ini.

Beranjak ke lantai paling atas yaitu lantai tiga, kurang begitu terasa suasana perkotaan di Korea Selatan. Namun unsur-unsur ciri khas Korea Selatan masih sangat terasa. Pada area lantai tiga lebih terfokus pada fungsi makan, minum, dan bercengkerama. Sebagaian besar kapasitas setiap areanya memfasilitasi duduk pengunjung dengan jumlah empat orang lebih. Konsep yang ditawarkan ada dua macam yaitu konsep duduk lesehan dan menggunakan bangku atau sofa panjang.

Dalam mewujudkan suasana Korea di dalam kafe untuk pengunjung dibutuhkan adanya tematik pada kafe. Tema merupakan hal utama yang perlu dipertimbangkan dalam menghasilkan sebuah estetika yang diantaranya dapat ditemui dalam sebuah karya seni atau desain (Gie, 1976). Maka dari itt, sebuah tema dalam desain interior sangat berperan penting agar seorang desainer lebih mudah untuk merancang sesuai dengan konsep yang lebih spesifik. Tema yang diusung oleh kafe Chingu adalah Korean street view yang diterapkan melalui elemen desain interior. Berdasarkan hasil forum grup diskusi yang dilakukan bersama para pengunjung ada beberapa elemen dalam ruang yang mampu membawa pengunjung pada suasana jalanan di kota besar di Korea yaitu mural, signage atau penunjuk arah, neon box, hanok yaitu arsitektural rumah tradisional Korea, dan elemen dekoratif. Berikut adalah deskripsi hasil analisis dan sintesis dari setiap elemen interior pada kafe Chingu yang berpengaruh dalam penciptaan suasana Korean Street View berdasarkan hasil komparasi antara pada forum grup diskusi dan pengamatan yang dilakukan secara langsung serta data dokumentasi.

\section{Mural}

Mural merupakan karya yang tertuang dalam bentuk lukisan besar yang dituangkan pada media datar dari sebuah sisi suatu bangunan atau objek tertentu (Gazali, 2017). Dewasa ini mural banyak di jumpai di jalanan, mulai dari mural floral, geometris sampai mural abstrak. Namun beberapa belakangan ini seni mural mulai akrab dengan dunia interior. Mural pada 
interior pada dasarnya memiliki sebuah tujuan penyampaian hal tertentu guna mewujudkan sebuah persepsi tertentu bagi yang melihatnya misalnya mampu memberikan kesan suasana tertentu dalam ruang (Rachmat \& Safitri, 2019). Mural yang baik harus dapat menunjukan ciri khas tema yang diterapkan pada interior. Kafe Chingu juga menggunakan mural sebagai elemen desain untuk menggambarkan kehidupan di perkotaan Korea. Objek wisata yang terkenal di Korea selatan dengan ciri khas mural di sepanjang jalannya adalah Ihwa Mural Village. Objek desa wisata ini berada di kota Seoul. Pengaplikasian mural pada objek wisata ini mulai dari tangga, dinding, sampai atap. Menurut salah satu peserta forum grup diskusi sudah banyak TV series dan drama Korea yang mengambil latar penayangan di lokasi ini, salah satu nya drama dengan genre comedy-romantic berjudul Rooftop Prince tahun 2012 (Gambar 2). Hal inilah yang membangun persepsi terhadap penontonnya terkait salah satu ciri khas Korea Selatan yaitu mural dengan karakter yang khas.


Gambar 2. Mural, Ihwa Mural Village dan drama rooftop prince di lhwa Mural Village Sumber: https://www.seoulkoreatour.net/places/korea-1/galleries/ihwa-art-village/ dan https://imbaztan.com/2014/09/15/seoul-day-3-ihwa-mural-village/

Dalam usaha mencapai suasana Korean street view, kafe Chingu mengaplikasikan mural pada dinding kafe yang bertema kehidupan perkotaan di Korea. Pengaplikasian mural pada kafe Chingu sangat variatif mulai dari gambar, dengan sentuhan huruf Korea atau Hangeul sampai gambar abstrak yang menggambarkan kondisi perkotaan Korea, seperti yang muncul pada salah satu sisi mural yang dihadirkan pada dinding di lantai satu (Gambar 3). 


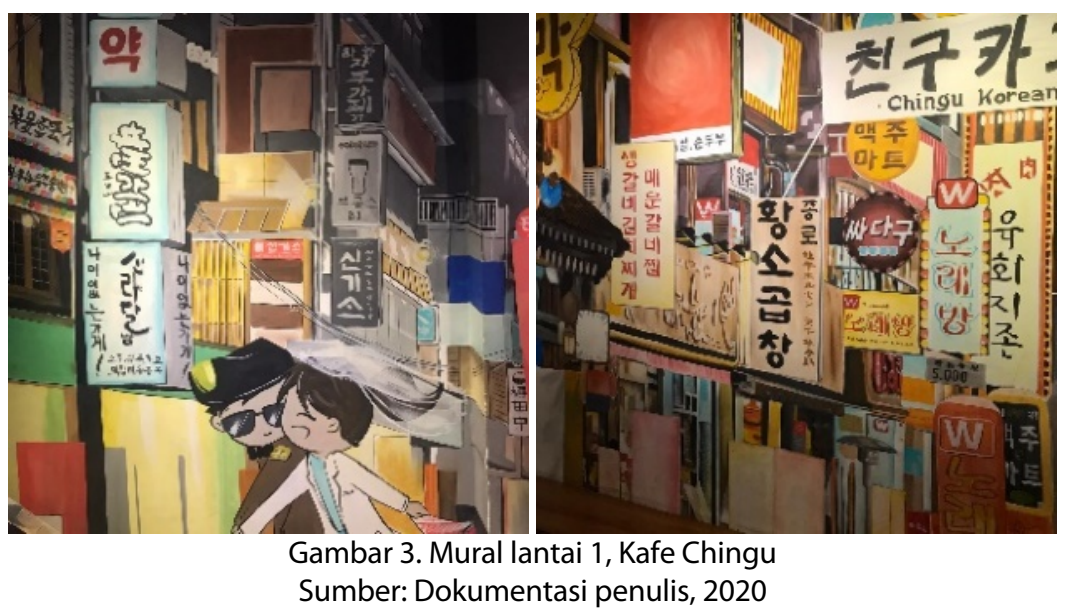

Jika diamati dengan seksama, ada cara yang unik yang diaplikasikan pada konsep mural tersebut. Pertama adalah metode gambar yang diterapkan menggunakan teknik perspektif yang penerapannya garis titik hilang berusaha menyesuaikan dengan sudut pandang lingkungan sekitar yang ada di lantai satu. Kondisi itu bertujuan agar gambar mural tersebut terkesan meruang dan menyatu dengan ruangan pada lantai satu. Kedua adalah karakter orang yang unik dan lucu yang menjadi ciri khas budaya Korea khususnya yang melekat pada kehidupan para remaja di sana. Ungkap salah satu pengunjung salah satu anggota forum grup diskusi yang merupakan pecinta traveling dan pernah berkunjung ke Korea, jika diperhatikan kembali dengan seksama, ada sebuah kesamaan tampilan mural tersebut dengan sebuah suasana jalanan yang sangat terkenal dikalangan pecinta traveling. Suasana jalanan yang ramai dengan hiruk pikuk usaha yang ada di pinggir jalan, mulai dari bangunan modern hingga yang masih mempertahankan bangunan tradisionalnya. Berhiaskan papan nama, lampu, dan neon box yang memeriahkan suasana sepanjang jalan. Kondisi dalam mural tersebut serupa dengan kondisi jalan Mangnidan-gil yang berada di Mangwon, Mapogu, Seoul Korea Selatan (Gambae 4). Tak heran jika pengunjung semakin kental merasakan suasana jalanan perkotaan di Korea pada lantai satu kafe ini. 


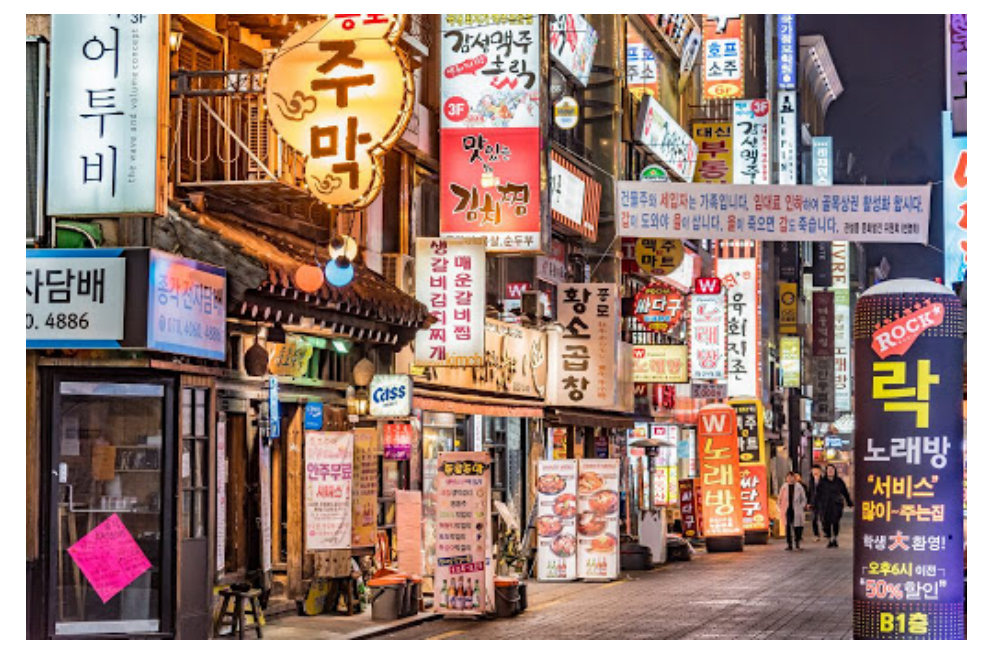

Gambar 4. Foto jalan Mangnidan-gil, Mangwon, Mapo-gu, Seoul-Korea Selatan Sumber: http://www.panorama-magz.com/newsflash/5-jalanan-trendi-di-korea-selatan

\section{Signage}

Salah satu ciri khas suasana perkotaan di Korea lainya menurut diskusi para pengunjung dalam forum grup diskusi yaitu signage atau petunjuk arah jalan. Signage atau petunjuk arah yang berada di perkotaan Korea biasanya dilengkapi dengan lampu jalan yang berada diatasnya. Selain itu bentuknya yang khas pada aplikasi bentuk dan warna serta penggunaan dua bahasa. Papan petunjuk arah tersebut baris bagian atasnya menggunakan bahasa Korea yang bertuliskan huruf hangeul, sedangkan di bagian baris bawahnya masih dengan arti yang sama namun diaplikasikan menggunakan huruf alfabet berbahasa Inggris (Gambar 5). Menurut salah satu peserta forum, ciri khas ini sering kali muncul melalui tayangan reality show, drama Korea, konten vlog dan juga video klip K-Pop, serta artikel para traveling blogger.


Gambar 5. Signage atau petunjuk arah di Insa-Dong Street Seoul, Korea

Sumber: http://www.jacqsowhat.com/2013/07/seoul-korea-day-4-insadong-sinchon-ewha.html dan https://www.tellerreport.com/news/--seoul-to-pyongyang-signs-to-stand------north-south-railway-first-steps.rytliYZWN.html

Kafe Chingu menerapkan ciri khas suasana perkotaan Korea dengan adanya signage atau petunjuk arah dengan bentuk, warna, tulisan serta dua bahasa yang serupa. Selain itu juga dengan lampu penerangan di atasnya yang bertujuan melengkapi situasi keadaan jalan di perkotaan Korea dalam interior kafe. Kondisi tersebut dapat dilihat pada Gambar 6. Posisi 
signage ini terletak pada area makan lantai dua yang sekaligus menunjukan bahwa masih ada area duduk lain dengan bernamakan daerah-daerah yang terkenal di Korea selatan. Skala signage yang diterapkan pada interior diperkecil karena menyesuaikan proporsi volume ruang. Hal ini juga dapat memperkuat konsep Korean street view agar pengunjung tetap dapat merasakan suasana perkotaan Korea yang dibawa ke dalam interior kafe.
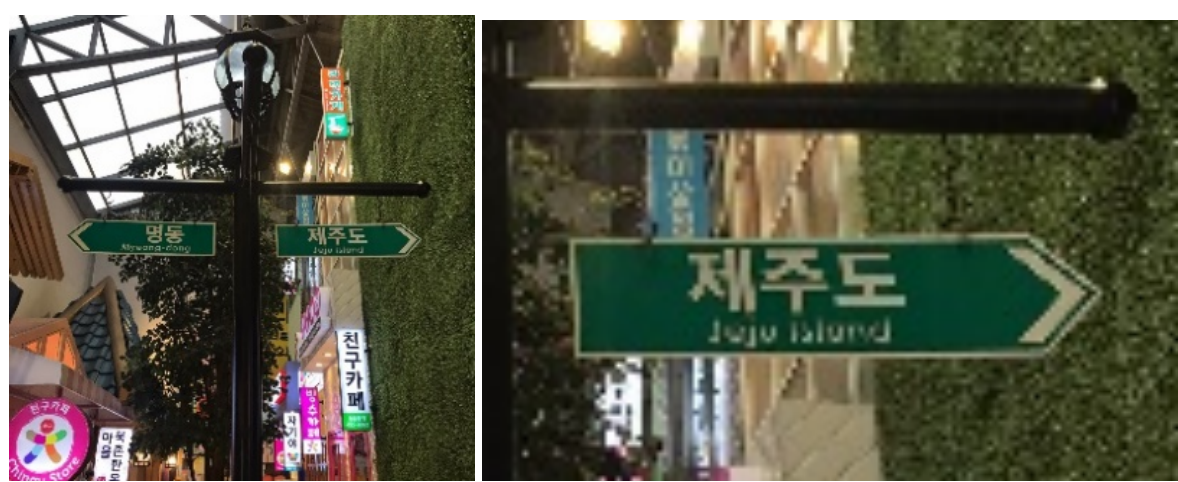

Gambar 6. Signage atau petunjuk arah pada interior kafe Chingu Sumber: Dokumentasi penulis, 2020

\section{Neon Box}

Neon box menjadi salah satu objek yang dapat mendeskripsikan suasana di perkotaan Korea. Sepanjang jalanan kota atau pusat belanja di Korea biasa dihiasi dengan neon box yang bermacam ukuran dan jenis dengan tulisan berhuruf Hangeul. Gambaran ramainya perkotaan Korea dengan hiasan neon box sering kali di dapatkan pada kanal youtube vlogger Indonesia maupun luar negeri. Salah satu kanal youtube yang menampilkan suasana perkotaan atau pusat belanja Korea adalah seoulwalker (Gambar 7). Banyak para pecinta Korea mengenal Korea tanpa harus berpergian langsung ke Negara ginseng ini salah satunya melalui tayangan tersebut yang ada di internet. Hal tersebut dibenarkan oleh sebagian besar pengunjung saat berdiskusi dalam forum grup diskusi.

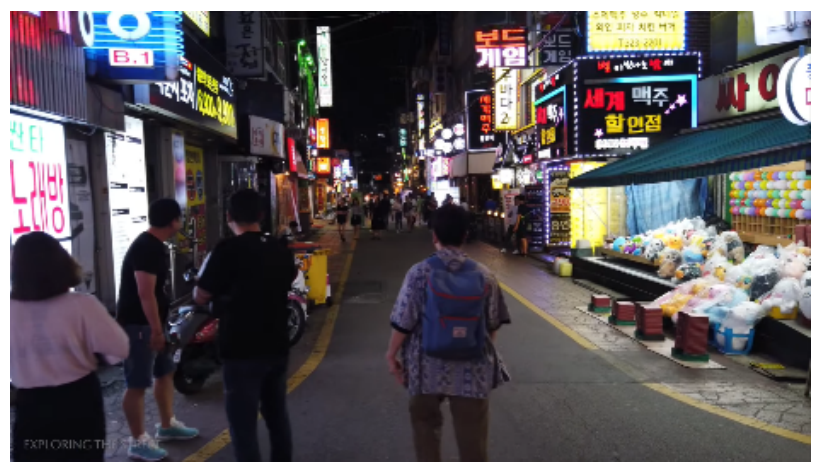
Sumber: https://youtu.be/H80yJ1pl8UQ 
Bagian Seoul yang terkenal dengan pusat belanja dan wisatanya adalah Itaewon. Belakangan ini Itaewon semakin diperbincangkan para penggemar Korea karena salah satu drama Korea yang cukup sukses berlokasi disini yang berjudul Itaewon Class (Gambar 8). Pada kedua sumber tontonan para pecinta Korea tersebut dapat terlihat bahwa meriahnya lampu berpadukan dengan neon box berhuruf hangeul di atas bangunan-bangunan pertokoan dan kafe menghiasi sepanjang pinggiran jalan.

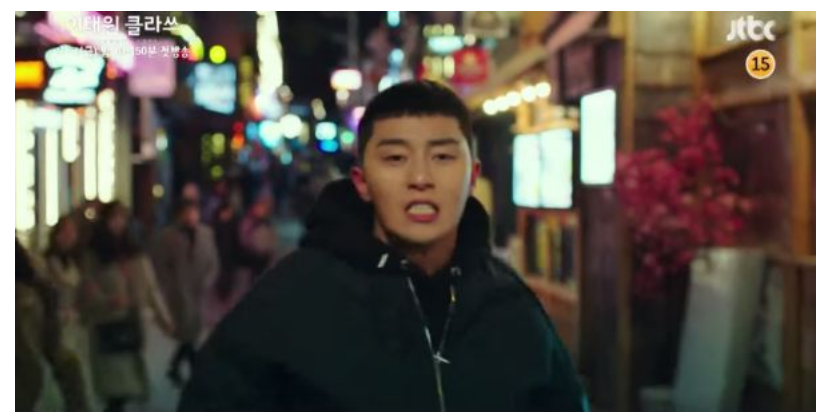

Gambar 8. Cuplikan Drama Korea Itaewon Class di Itaewon street Sumber: https://www.dramabeans.com/2020/01/park-seo-joon-runs-through-the-colorful-streets-in-itaewonclass/

Kehadiran neon box itulah yang juga dimanfaatkan sebagai pelengkap dalam mewujudkan suasana jalanan perkotaan Korea dalam persepsi pengunjung Kafe Chingu. Neon box pada kafe Chingu diletakan berdampingan dengan mural dinding dan juga diberi sentuhan huruf Hangeul di bagian atas dinding sepanjang sisi ruas utama sirkulasi pada lantai dua (Gambar 9). Elemen interior pada area ini menyerupai pusat perbelanjaan di Korea dimana terdapat neon box di sisi kanan dan kiri jalan tiap bangunannya dengan komposisi warna-warna yang kontras agar menyerupai susana jalanan kota Korea pada umumnya. Suasana ini sering dimanfaatkan oleh pengunjung untuk mengambil gambar atau berfoto bersama.
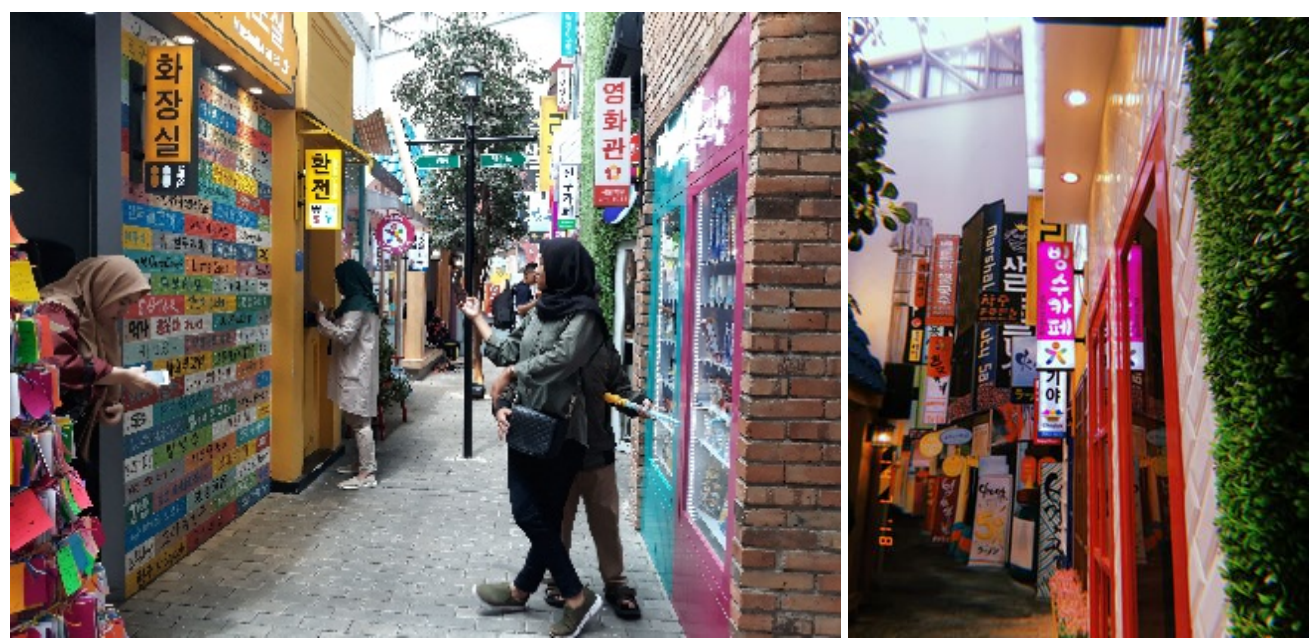


\section{Hanok}

Hanok merupakan sebutan untuk rumah tradisional Korea. Struktur atau material yang digunakan pada bangunan ini biasanya material alam berupa kayu, batu, tanah, dan jerami. Hanok seringkali muncul pada serial TV atau drama Korea yang bertema kolosal.
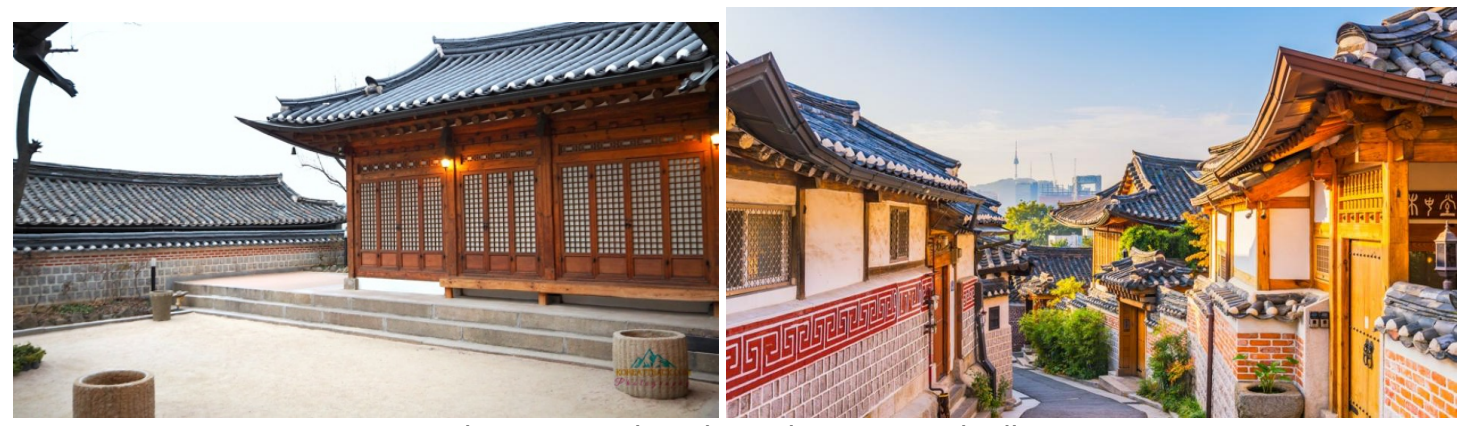

Gambar 10. Rumah tradisional Korea, Hanok village Sumber: https://www.koreattrack.com/bukchon-hanok-village.html dan https://traveltriangle.com/blog/bukchon-hanok-village/

Hanok village merupakan salah satu destinasi wisata yang sering dikunjungi oleh wisatawan baik dalam maupun luar negeri. Sepanjang jalan diwilayah ini sangat kental dengan suasana tradisional perumahan bergaya tradisional Korea, baik di sisi kanan maupun kiri jalan seperti yang tampak pada Gambar 10. Selain itu, Hanok Village terkenal di kalangan masyarakat diantaranya merupakan beberapa pengunjung yang bergabung saat diskusi dalam forum. Mereka menyatakan hal itu karena Hanok Village merupakan salah satu tempat pengambilan gambar drama Korea yaitu Personal Taste yang dibintangi artis Korea ternama, Lee Minho, yang mereka idolakan. Nama artis tersebut sudah tidak asing di telinga para penontonya di Indonesia (Gambar 11). 




Gambar 11. Tayangan drama Personal Taste di Hanok Village Sumber: Dokumentasi penulis, 2020

Ketenaran artis dan lokasi pengambilan gambar yang terkenal itulah pada akhirnya juga tak luput dari Kafe Chingu dalam melengkapi terbangunya suasana Korea dalam ruang terhadap pengunjung. Sebuah rumah tradisional Korea dengan bentuk yang sederhana dihadirkan dalam skala yang disesuaikan dengan volume ruang yang ada. Agar lebih menarik pandangan, pada bagian atap diaplikasikan warna biru muda yang begitu kontras dengan bagian lain di bagian bawah yang dominan bermaterial kayu serupa dengan material yang digunakan pada Hanok di Korea (Gambar 12).



Gambar 12. Penerapan bentuk Hanok pada salah satu area duduk kafe Chingu Sumber: Dokumentasi Penulis, 2020

Menurut para pengunjung dalam forum grup diskusi, salah satu keunikan lain yang terdapat pada miniatur bangunan Hanok yang berada didalam ruang Kafe Chingu adalah pengaplikasian detail arsitektur pada pintu. ti-sal, wanja-sal, kyukja-sal, aja-sal, guija-sal, guigapsal merupakan nama-nama ornamen yang khas dimiliki dan diterapkan pada bangunan tradisional Hanok maupun bangunan modern di Korea. Jendela dan pintu adalah bagian yang paling sering diterapkan adanya ornamen-ornamen khas tersebut (Viviana \& Fatimah, 2019). Ornamen hanok yang dipakai dalam kafe Chingu yaitu ornamen Ti-sal (Gambar 13). Ornamen Ti-sal bisa dikatakan adalah ornamen yang paling sederhana diantara 
ornamen lainnya. Ornamen ini terdiri dari susunan garis vertikal pada sebuah bidang datar persegi panjang yang dipadukan dengan kumpulan garis horizontal dengan perbedaan jarak susunan sehingga membuat sebuah wilayah masing-masing yaitu bagian atas, tengah, dan bawah.

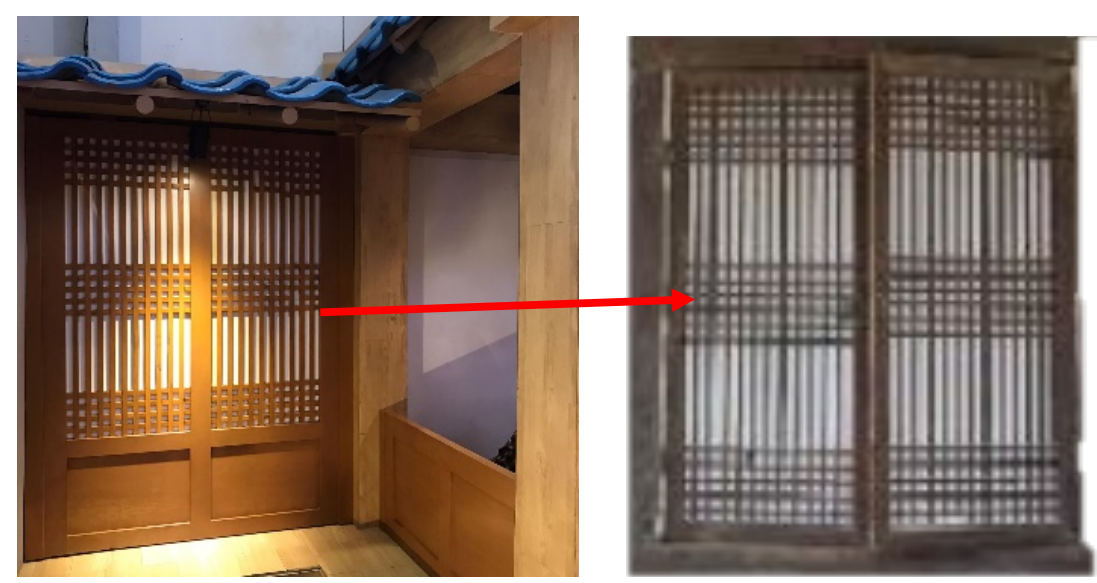

Gambar 13. Ornamen ti-sal Hanok pada kafe chingu dan pada publikasi jurnal Sumber: Dokumentasi penulis, 2020; Kang, Seungmook. Et al., 2010

\section{Elemen Dekoratif}

Elemen unik lainnya yang menjadi ciri khas Chingu dengan tema Korean street view dalam membangun suasana tematik pada pengunjung berdasarkan hasil diskusi adalah elemen dekoratif yang paling kuat. Dekoratif merupakan suatu ornamen yang dibuat dengan media tertentu yang biasanya memiliki tujuan sebagai pelengkap dan memperindah suatu objek baik berupa benda atau ruang (Utami \& Suwarno, 2019). Kafe chingu memiliki beberapa benda dekoratif sebagai penunjang elemen interior lain untuk memberikan pengalaman dan suasana yang berbeda dari kafe lain. Salah satu destinasi wisatawan di negeri gingseng ini ialah Busan Gamcheon Culture Village. Ikon tempat ini menjadi salah satu yang membangun persepsi pengunjung dalam menciptakan suasana jalanan perkotaan Korea dalam interior kafe Chingu.

Salah satu anggota forum diskusi menyatakan bahwa ada sebuah sisi jalanan di Gamcheon Busan yang menyerupai salah satu elemen dekoratif yang ada di interior Kafe Chingu, yaitu sebuah tempelan lukisan papan kecil pada dinding yang berwarna warni yang diatur berirama sepanjang sisi dinding tertentu (Gambar 14). Kontras warna pada dinding inilah yang menarik pandangannya dan sering kali menjadi tempat berfoto karena mencirikan lokasi wisata setempat. Gamcheon Busan merupakan lokasi yang sangat terkenal di dunia 
pariwisata di Korea.



Gambar 14. Gamcheon culture village, Busan

Sumber: https://livingnomads.com/2018/05/busan-2-day-itinerary/gamcheon-cultural-village-2/

Seperti yang tampak pada Gambar 15, konsep dekorasi jalanan pada desatinasi wisata Korea itulah yang dijadikan salah satu bagian pembentuk tema Korean street view yang ada pada kafe Chingu. Hanya saja yang membedakan adalah dari segi penerapan dimensi dan tema lukisan. Dimensi dibuat lebih kecil dan padat karena menyesuaikan kesediaan tempat yang ada dengan susunan yang lebih rapat. Penggunaan warna masih menyerupai dengan menggunakan warna yang meriah dan kontras. Lukisan yang ditampilkan lebih kearah penggunaan kata-kata bahasa Korea dan Inggris bermaknakan ciri khas Korea menggunakan paduan huruf hangeul dan alfabet.

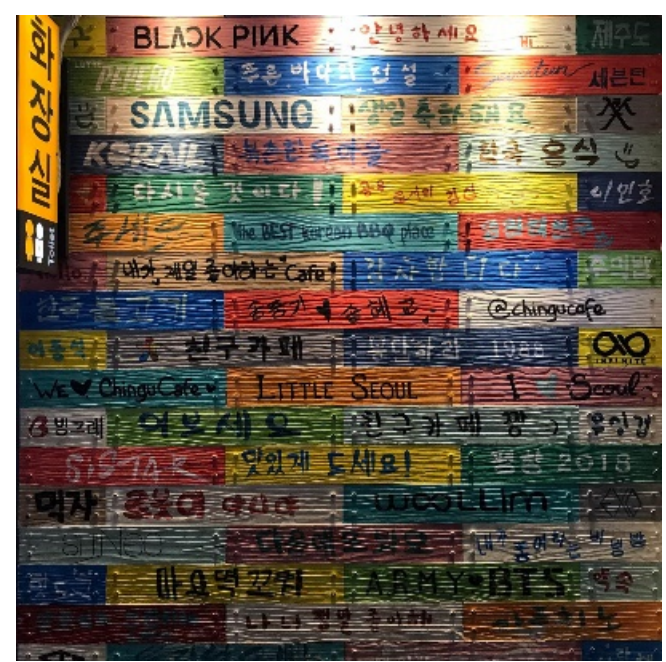

Gambar 15. Elemen dekoratif dinding Sumber: Dokumentasi penulis, 2020

Selain Jepang, Korea selatan juga identik dengan bunga sakura pada musim seminya. Salah satu festival bunga sakura terbesar adalah Cherry Blossom Festival yang di gelar di Jinhae, Korea Selatan (Gambar 16). Bunga sakura di daerah ini banyak terdapat dipinggiran sungai diatas 
trotoar yang berdampingan langsung dengan jalan raya. Pada saat festival ini berlangsung banyak sekali warga yang menikmati keindahan berseminya bunga sakura di sepanjang jalan pinggiran sungai.

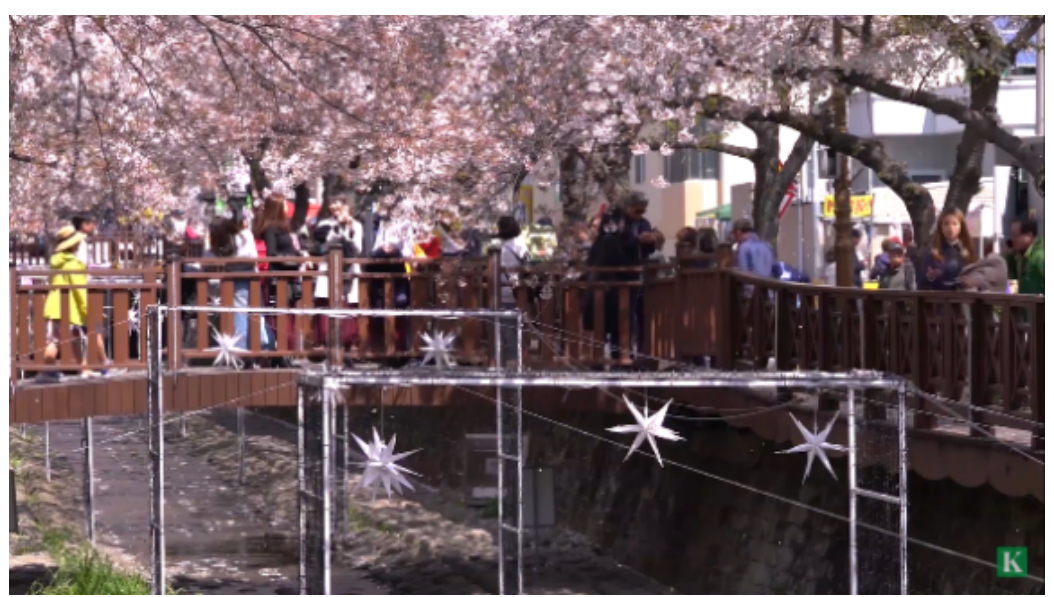

Gambar 16. Festival bunga sakura pada kanal youtube the Korea times Sumber: https://www.youtube.com/channel/UCiOrOk3NQGW2GafvjLJknMA

Keadaan di Jinhae tersebut tak luput dari salah satu usaha kafe Cingu dalam membangun suasana perkotaan Korea dalam ruang terhadap pengunjung. Pada area semi outdoor lantai dua, kafe Chingu menerapkan elemen dekoratif berupa bunga sakura yang menjadi ciri khas kota Korea saat musim semi. Batang pohon dengan kayu yang kering berhiaskan bunga sakura sintetis diterapkan sebagai elemen dekoratif pada interior kafe yang menjuntai di bagian atas area duduk seperti yang terlihat pada gambar 17.



Gambar 17. Sakura pada kafe chingu

Sumber: Dokumentasi penulis, 2020

Menurut para pengunjung dalam forum grup diskusi, elemen dekoratif lain yang mengangkat tema perkotaan Korea lainnya yaitu adanya sebuah kotak yang menyerupai mesin minuman di dalam kafe. Mesin penjual otomatis memang sering dijumpai di perkotaan besar Korea 
selatan. Mesin ini sering terdapat di sepanjang jalan perkotaan, pusat perbelanjaan maupun di stasiun-stasiun kereta (Gambar 18).


Gambar 18. Dekorasi mesin minuman di Kafe Chingu dan mesin penjual minuman otomatis di pusat Kota Korea

Sumber: Dokumentasi penulis dan http://alwaysawakeinseoul.blogspot.com/2013/03/south-korean-vendingmachines.html

Mesin minuman pada Kafe Chingu digunakan hanya sebagai elemen dekorasi atau pajangan semata berisikan makanan dan minuman yang merupakan produk-produk yang berasal dari Korea. Material yang digunakan pun berbeda dengan yang sesngguhnya. Jika mesin minuman pada umumnya menggunakan alumunium, pada Kafe Chingu mesin minuman menggunakan material multipleks dengan lapisan akhir cat semprot dengan warna yang sangat mengundang perhatian mata para pengunjungnya. Ditambah lagi dengan adanya neon sign yang membentuk huruf bertuliskan nama kafe ini seperti yang terlihat pada Gambar 18.

Selain mesin penjual otomatis, berdasarkan hasil diskusi pengunjung dalam forum bahwa elemen dekoratif lainya yang sangat memberikan ciri khas kondisi perkotaan Korea Selatan pada Kafe Chingu adalah sebuah tempat duduk dengan penutup atap yang sangat menyerupai dengan halte yang ada dipinggiran jalan perkotaan di Korea. Korea Selatan sangat dikenal dengan kemudahan transportasi umumnya. Masyarakat di sana sangat maksimal dalam memanfaatkan transportasi umum diantaranya kereta listrik atau bus. Jalur transportasinya sangat tertata rapi dan tertib sehingga banyak sekali terdapat tempat menunggu serta pemberhentian bus disepanjang jalanan diperkotaan besar di Korea selatan.

Budaya bertransportasi massal pada masyarakat Korea juga tak lepas dari tayangan Drama negeri ini. Kebiasaan keseharian menggunakan transportasi umum. Bus menurut salah satu 
pengunjung yang tergabung dalam forum grup diskusi tercermin dalam cerita asmara yaitu Because This is My First Life yang ditontonnya (Gambar 19). Pernyataan tersebut juga sependapat oleh beberapa pengunjung lainya yang baru teringat terhadap adegan dalam tayangan drama Korea tersebut.



Gambar 19. Foto tayangan Drama Because This is My First Life Sumber: https://www.hellokpop.com/review/kdrama-review-because-this-is-my-first-life/

Pada drama tersebut, halte bus dijadikan sebuah ikon tempat bertemunya muda mudi yang sedang kasmaran yang diperankan oleh aktris Jung So Min dan aktor Lee Min Ki. Budaya bertransportasi umum tersebut pada akhirnya melekat di para penontonnya, termasuk di Indonesia. Ikon objek transportasi umum ini akhirnya juga dihadirkan sebagai cara membangun suasana jalanan perkotaan Korea dalam interior kafe Chingu.



Gambar 20. Elemen dekoratif Halte di Kafe Chingu Sumber: Dolumentasi penulis, 2020

Kondisi asli halte yang ada di pinggir jalan kota di Korea dimensinya cukup besar bisa menampung beberapa orang. Berbeda dengan elemen dekoratif yang menyerupai halte pada kafe Chingu seperti yang terlihat pada Gambar 20, bentuk penerapannya dengan mengecilkan dimensi dan komposisinya disesuaikan dengan ketersediaan luasan ruang yang ada. Bentuk dekorasi tersebut sangat identik dengan kondisi yang sebenarnya, terdapat sebuah bangku panjang dengan papan informasi yang ada dibelakang bangku lalu 
Serat Rupa Journal of Design, July 2021, Vol.5, No.2: 166-185

E-ISSN: 2477-586X, ISSN: 2338-3348 | https://doi.org/srjdv5i2.2836 | Received: 13-08-2020 Accepted: 03-04-2021

Mahendra Nur Hadiansyah, Dessy Fitrah Ramadhani

Kajian Elemen Pembentuk Suasana Ruang Bertema Korean Street View pada Interior Kafe Chingu di Bandung

bertutupkan kanopi dibagian atasnya. Keberadaan halte mini ini melengkapi suasana yang bertemakan Korean Street View pada interior Kafe Chingu.

\section{PENUTUP}

Berdasarkan pembahasan yang ada, akhirnya dapat disimpulkan bahwa dalam menciptakan tema Korean Street View untuk memberikan pengalaman dan dapat menarik pengunjung dihadirkan melalui beberapa elemen interior yaitu, mural, signage atau petunjuk arah, neon box, arsitektural rumah tradisional Korea atau hanok dan beberapa elemen dekoratif seperti dinding dengan papan bertuliskan huruf Hangeul, pohon bunga sakura, dan objek yang menyerupai mesin penjual otomatis. Dalam penerapannya untuk menghadirkan kesan di luar ruang dari suasana jalanan di perkotaan Korea selatan adalah menggunakan cara pengaturan komposisi objek elemen interior melalui pengecilan dimensi dari ukuran aslinya yang skalanya disesuaikan dengan volume ruang yang tersedia. Kondisi tersebut pada akhirnya menghasilkan sebuah sajian interior yang unik melalui usaha duplikasi objek dari ikon, ciri khas, dan stereotipe yang muncul dalam persepsi masyarakat Indonesia terhadap budaya Korea. Referensi pada hallyu wave merupakan salah satu tolok ukur utama dalam menciptakan objek-objek tersebut menjadi elemen interior di Kafe Chingu. Sehingga memang tepat dan pantas jika kafe Chingu dijuluki sebagai miniatur Seoul atau The Little of Seoul yaitu merupakan ibu kota negara Korea Selatan.

\section{DAFTAR PUSTAKA}

Anggito. A dan Setiawan. J (2018). Metodologi Penelitian Kualitatif. Kab. Sukabumi: CV jejak. Gazali, M.V. (2017). Seni Mural Ruang Publik dalam Konteks Konservasi. Jurnal Imajinasi, Vol 11 No.1, 69-76. DOI: https://doi.org/10.15294/imajinasi.v11i1.11190

Gie, T. Liang (1976). Garis Besar Estetik (Filsafat Keindahan). Yogyakarta: Karya.

Hadiansyah, Mahendra N., et al. "The Role of Interior Design Elements in Attracting K-pop Lovers at Mujigae Restaurants in Bandung." 6th Bandung Creative Movement 2019, Bandung, Indonesia, October 2019. Telkom University, 2019, pp. 260-264.

Hadiansyah, Mahendra N. \& Hendrawan, Alfin S. (2020). Persepsi Ruang Pada Interior Restoran Donwoori Bandung. Waca Cipta Ruang: Jurnal Ilmiah Desain Interior, Volume 6 Nomor 2 (2020) Hal. 42-50. DOI: https://doi.org/10.34010/wcr.v6i2.3436

Kusumowidagdo, Astrid. (2005). Peran Penting Perancangan Interior Pada Store Based Retail. 
Dimensi Interior, 3(1). DOI: https://doi.org/10.9744/interior.3.1.

Rachmat, G., \& Safitri, R. (2019). Fenomena Mural Sebagai Pembentukan Suasana Interior Cafe Resto . Jurnal Atrat, Vol 7 no.3. diunduh pada: https://jurnal.isbi.ac.id/index.php/atrat/article/view/1084/698

Sari, I.C., \& Jamaan, A. (2014). Hallyu Sebagai Fenomena Transnasional. Jurnal Online Mahasiswa bidang ilmu social dan ilmu politik, Vol.1 No.1, 1-14. ISSN: 2355-6919

Utami, S., \& Suwarno, S. (2019). PENINGKATAN KEMAMPUAN MOTORIK HALUS DENGAN MENGGAMBAR DEKORATIF PADA KELOMPOK BERMAIN (KB) BUDI UTOMO PULOKULON KECAMATAN PULOKULON KABUPATEN GROBOGAN.DAR EL-ILMI : Jurnal Studi Keagamaan, Pendidikan Dan Humaniora, 6(1), 185-204. Retrieved from http://e-jurnal.unisda.ac.id/index.php/dar/article/view/1613

Viviana, N., \& Fatimah, D. (2019). Penerapan Ornamen Residensial Pada Kafe Korean House Bandung. Unikom. 